\title{
Physical exercises and weight loss in obese patients help to improve uric acid
}

\author{
Jun Zhou ${ }^{1}$, Yu Wang ${ }^{2}$, Fan Lian ${ }^{1}$, Dongying Chen ${ }^{1}$, Qian Qiu ${ }^{1}$, Hanshi Xu ${ }^{1}$, Liuqin \\ Liang ${ }^{1}$ and Xiuyan Yang ${ }^{1}$ \\ ${ }^{1}$ Department of Rheumatology \& Clinical Immunology, The First Affiliated Hospital of Sun Yat-sen University, Guangzhou \\ 510080, China \\ ${ }^{2}$ Department of Interventional Oncology, The First Affiliated Hospital of Sun Yat-sen University, Guangzhou 510080, China \\ Correspondence to: Fan Lian, email: lianfan_l@hotmail.com \\ Keywords: hyperuricemia; BMl; physical activity; waist circumference
}

Received: July 13, $2017 \quad$ Accepted: August 17, $2017 \quad$ Published: October 25, 2017

Copyright: Zhou et al. This is an open-access article distributed under the terms of the Creative Commons Attribution License 3.0 (CC BY 3.0), which permits unrestricted use, distribution, and reproduction in any medium, provided the original author and source are credited.

\section{ABSTRACT}

Objective: to assess the impact of longitudinal change of the overweight and physical activity on hyperuricemia.

Methods: We performed a retrospective cohort study. Demographic information, clinical features, laboratory findings, body weight and physical exercises pattern were documented.

Results: Altogether 4678 cases of hyperuricemia were enrolled. The median aged males were most affected. Individuals in the middle age had the highest prevalence of being overweight (2501/3382, 74.0\%). Middle aged with $B M I \geq 25 \mathrm{~kg} / \mathrm{m}^{2}$ were more likely to lose weight $(963 / 2807,34.3 \%)$. BMI and waist circumference control helped to reduce serum uric acid. Overweight population was more likely to use urate-lowering or uricosuric medication (3025/3382, 89.4\%). Intermediate and heavy activity were associated with bigger SUA improvement. Patients in the age of 35-60 were more likely to do physical exercises than the others.

Conclusion: Being overweight is strongly associated with hyperuricemia. Successful weight control was correlated with significant uric acid reduction. Intermediate to heavy physical activity helps to reduce waist circumference and SUA. In the hyperuricemia population, obese, middle aged men were the most affected, and also the most likely to do more exercises and get their bodyweight back to normal.

\section{INTRODUCTION}

High levels of serum uric acid (UA) has been rapidly increasing in the general population [1,2]. Accumulating clinical evidence suggests that hyperuricemia is associated with various metabolic disorders [3]. Similar prevalence has been found in China [4]. There are studies indicating that being overweight might be related with different metabolic burden [5].

Obesity [body mass index $(\mathrm{BMI}) \geq 30 \mathrm{~kg} / \mathrm{m}^{2}$ ] and central adiposity [waist circumference (WC) $\geq 80 \mathrm{~cm}$ women (WCF), $\geq 90 \mathrm{~cm}$ men (WCM)] are prodromal conditions for metabolic syndrome (MetS) [6, 7]. Previous study showed that intensive physical exercises may prevent athletes from developing metabolic syndrome (MetS). [8]. And some reports suggested that physically active lifestyle would help to improve cardiometabolic disorders. $[9,10]$.

Recent studies suggested that SUA was a key element underlying excess fat storage $[11,12]$. Intracellular $\mathrm{UA}$ is an inhibitor for adenosine monophosphate protein kinase (AMPK) activity. When AMPK activity is reduced, fat oxidation is down-regulated, and excess fat is infiltrated [13]. 
On the other hand, adipose tissue can also produce UA. Adipocytes has xanthine oxidoreductase (XO), and this enzyme is responsible for UA production [14].

Optimal treatment of hyperuricemia is to reach a target level of SUA $<6.0 \mathrm{mg} / \mathrm{dl}$. For many years, allopurinol and benzbromarone were the main uratelowering therapies. Febuxostat, a non-purine XO inhibitor, was launched recently. However, the ability of these therapies to lower SUA was not so promising in some obese patients. Obesity is an important factor of hyperuricemia. Weight control is likely to reduce SUA level and associated costs of medication.

As the prevalence of hyperuricemia correlated with the prevalence of being overweight, the influence of bodyweight control and physically active lifestyle on hyperuricemia treatment remains unclear in China. We carried out the present study to assess the impact of longitudinal change of overweight and physical activity on hyperuricemia.

\section{RESULTS}

Among the 4678 cases of hyperuricemia recorded, the majority were male $(3144 / 4678,67.2 \%)$, and the female accounted for only one third (1534/4678, 32.8\%). The median age was $42.3 \pm 10.6$. Participants at the age of $35-60$ years old had the highest prevalence (2807/4678, $60.0 \%$ ) of hyperuricemia among the three groups. And participants at the age of 18-35 years old had the lowest prevalence $(863 / 4678,18.4 \%)$ of hyperuricemia among the three groups. The patients were all with normal kidney function. They all followed the dietary guidance including alcohol and smoking restriction.

The prevalence of being overweight (3382/4678, $72.3 \%$ ) was increased in hyperuricemia patients, especially the overweight cases with abnormal waist circumference (2854/4678, 61.0\%).

The characteristics of the subjects at baseline were shown in Table 1. Male sex, hypertension, abnormal waist circumference, increased blood measures of fasting plasma glucose (FPG), triglyceride (TG) and decreased high density lipoprotein cholesterol (HDL-C) were strongly correlated with being overweight. Individuals at the age of 35-60 had the highest prevalence of being overweight, and participants $>60$ years old made up of $53.5 \%$ of the normal body weight group $(53.5 \%, 693 / 1296)$.

Patients with higher BMI had higher SUA levels at baseline.

During the 2 years of follow-up period, we observed the effects of bodyweight change on uric acid levels (Table 2). Participants with $B M I \geq 25 \mathrm{~kg} / \mathrm{m}^{2}$ were more likely to lose weight when at the age of 35-60 years (963/2807, $34.3 \%)$. SUA improvement was associated with BMI and waist circumference reduction. The SUA level was significantly decreased in the $\Delta \mathrm{BMI}$ from $\geq 25 \mathrm{~kg} / \mathrm{m}^{2}$ to $<25 \mathrm{~kg} / \mathrm{m}^{2}$ group as compared to the other three groups.
Subjects from the normal-to-normal-BMI group showed significant SUA improvement as well. Details of the patients were as follows:

1. Patients in the group of $\Delta$ BMI from BMI $<\mathbf{2 5} \mathbf{~ k g} / \mathbf{m}^{2}$ to $\geq \mathbf{2 5} \mathbf{~} \mathbf{~ g g} / \mathbf{m}^{2}$ : there were 35 patients $(35 / 178,19.7 \%)$ detected with normal SUA after two years, and all of these patients were on urate-lowering medication. The rest of the patients $(143 / 178,80.3 \%)$ in this group could not achieve normal uric acid level even though they took the urate-lowering medication.

2. Patients in the group of $\Delta$ BMI from $\geq \mathbf{2 5} \mathbf{~ k g} / \mathbf{m}^{\mathbf{2}}$ to $\geq \mathbf{2 5} \mathbf{~ k g} / \mathbf{m}^{2}$ : there were 775 patients $(775 / 2163$, $35.8 \%$ ) detected with normal SUA after two years, and none of them lost much weight. They all took the urate-lowering medication. Their improvement of uric acid was not correlated to bodyweight loss.

3. Patients in the group of $\Delta \mathbf{B M I}$ from $\mathbf{B M I}<\mathbf{2 5}$ $\mathbf{k g} / \mathbf{m}^{2}$ to $<\mathbf{2 5} \mathbf{~ k g} / \mathbf{m}^{2}$ : there were 843 patients $(843 / 1118,75.4 \%)$ detected with normal SUA after two years, in which 346 patients didn't take uratelowering medication $(346 / 843,41.0 \%)$. [The ratio for patients didn't take urate-lowering medication with the whole group was 346/1118, 30.9\%]. Though their improvement of uric acid was not correlated to bodyweight loss, it seemed that the uric acid level were more easily to be controlled if the patients were not overweight in the whole process.

4. Patients in the group of $\Delta \mathbf{B M I}$ from $\geq \mathbf{2 5} \mathbf{~ k g} / \mathbf{m}^{2}$ to $<\mathbf{2 5} \mathbf{~ k g} / \mathbf{m}^{2}$ : there were 1102 patients (1102/1219, $90.4 \%$ ) detected with normal SUA after two years, in which 311 patients didn't take urate-lowering medication $(311 / 1102,28.2 \%)$. [The ratio for patients didn't take urate-lowering medication with the whole group was 311/1219, 25.5\%].

All of the patients who didn't loss bodyweight, or with increased bodyweight after two years achieved normal SUA by taking urate-lowering agents.

The demographic and clinical parameters were included in the linear regression model. Male sex, bodyweight and waist circumference, elevated triglycerides were considered strongly associated factors with SUA change. As a factor, age did not reach statistical significance.

Patterns of use of urate-lowering agents are shown in Table 3.

The most common doses for allopurinol were 300 $\mathrm{mg}$ /day or lower, $40 \mathrm{mg} /$ day for febuxostat and $50-100$ $\mathrm{mg}$ /day for benzbromarone. A much higher proportion of urate-lowering or combined urate-lowering therapy and a lower proportion of uricosuric medication was found in overweight population. Patients with normal weight was more likely to be recommended lifestyle intervention (433/1296, 33.4\%) instead of urate-lowering prescription.

The association between physical activity and SUA are shown in Table 4. 
Table 1: Demographic characteristics and clinical features of overweight patients with hyperuricemia at baseline

\begin{tabular}{|c|c|c|c|}
\hline & BMI $<25 \mathrm{~kg} / \mathrm{m}^{2}(\mathrm{n}=1296)$ & $\mathrm{BMI} \geq 25 \mathrm{~kg} / \mathrm{m}^{2}(\mathrm{n}=3382)$ & $P$-value \\
\hline \multicolumn{4}{|l|}{ Age (years), Number (\%) } \\
\hline$>60$ & $693(45.8)$ & $315(9.3)$ & $<0.05$ \\
\hline $35-60$ & $306(23.6)$ & $2501(74.0)$ & $<0.05$ \\
\hline $18-35$ & $297(22.9)$ & $566(16.7)$ & $>0.05$ \\
\hline Sex (Male), Number (\%) & $459(35.4)$ & $2685(79.4)$ & $<0.05$ \\
\hline Sex (Female), Number (\%) & $837(64.6)$ & $697(20.6)$ & $<0.05$ \\
\hline $\begin{array}{l}\text { Waist circumference, } \mathrm{cm} \text {, } \\
\text { abnormal, Number }(\%)\end{array}$ & $45(3.5)$ & $2622(77.5)$ & $<0.05$ \\
\hline $\begin{array}{l}\text { Elevated blood pressure, } \\
\text { Number }(\%)\end{array}$ & $576(44.4)$ & $2188(64.7)$ & $<0.05$ \\
\hline $\mathrm{SBP}, \mathrm{mm} \mathrm{Hg}$ & $137.1 \pm 26.4$ & $143.4 \pm 29.5$ & $>0.05$ \\
\hline $\mathrm{DBP}, \mathrm{mmHg}$ & $68.7 \pm 11.5$ & $72.4 \pm 13.8$ & $>0.05$ \\
\hline Low HDL, $n$ & 491(37.9) & $2653(78.4)$ & $<0.05$ \\
\hline Elevated TG, $n$ & $213(16.4)$ & $2759(81.6)$ & $<0.05$ \\
\hline Elevated fasting glucose, $n$ & $317(24.5)$ & $2036(60.2)$ & $<0.05$ \\
\hline Serum UA level, mg/dl & $8.05 \pm 1.24$ & $8.38 \pm 1.37$ & $>0.05$ \\
\hline
\end{tabular}

Abnormal waist circumference: $\geq 90 \mathrm{~cm}$ (male) or $\geq 80 \mathrm{~cm}$ (female); Elevated blood pressure : $\geq 130 / 85 \mathrm{~mm} \mathrm{Hg}$ or on hypertension prescription; low HDL : $<1.03 \mathrm{mmol} / \mathrm{L}$ (male) or $<1.30 \mathrm{mmol} / \mathrm{L}$ (female); elevated TG : $\geq 2.28 \mathrm{mmol} / \mathrm{L}$ (within $4 \mathrm{~h}$ since last meal) and $\geq 1.7 \mathrm{mmol} / \mathrm{L}$ (above $4 \mathrm{~h}$ since last meal) or on lipid lowering drugs; elevated fasting glucose: $\geq 7.8 \mathrm{mmol} / \mathrm{L}$ (within $4 \mathrm{~h}$ since last meal) and $\geq 5.6 \mathrm{mmol} / \mathrm{L}$ (above $4 \mathrm{~h}$ since last meal) or on glucose lowering prescription; $B M I$ : body mass index, $U A$ : uric acid, TG: triglycerides, $H D L$ : high-density lipoprotein, SBP: systolic blood pressure, DBP: diastolic blood pressure.

Table 4 presents the relationship of activity and SUA level. By comparing the SUA level before and after intervention of medication and physical activity, we found that, all the groups improved, however, the number of patients reach the target of SUA $<6.0 \mathrm{mg} / \mathrm{dl}$ were significantly different. After we run the regression model, physical activies didn't reach statistical significance. Then we narrowed down to the patients in the group of $\Delta B$ MI from $\geq 25 \mathrm{~kg} / \mathrm{m} 2$ to $<25 \mathrm{~kg} / \mathrm{m} 2$, there were 1102 patients $(1102 / 1219,90.4 \%)$ detected with normal SUA after two years, in which 311 patients didn't take uratelowering medication $(311 / 1102,28.2 \%)$. In these patents, 259 cases took medium or heavy activities. Our data may not significantly associate intensive physical activities with SUA change directly, but physical activies helped to improve BMI and waist circumference control, and partly contributed to SUA change. In our observation, patients in the age of 35-60 were more likely to do physical exercises than the others.

\section{DISCUSSION}

In this study from south China, we found that being overweight is strongly associated with hyperuricemia.
The participants with higher levels of serum uric acid were more likely to be overweight and had abnormal waist circumference. And obese patients were easier to diagnosed hyperuricemia. Consistent with our results, several previous studies have also shown the relationship between overweight and uric acid, and that reduction of BMI could help improve SUA levels [21-24].

In the hyperuricemia population, obese, middle aged men were the most affected in our study. Young female were rarely involved. However, there were substantial shifts in the prevalence of hyperuricemia from middle and aged people to adolescents. Simultaneously, the obese adolescents had higher uric acid than non-obese adolescents. It suggested that we should pay more attention to monitor elevated SUA in young patients and the problem of adolescent obesity.

Interestingly, after 2 years observation, we found that successful weight control, mostly $>10 \mathrm{~kg}$ weight reduction, was correlated with significant uric acid reduction, which was consistent with the report by Dalbeth $\mathrm{N}$, et al., that huge weight loss in severe obesity (BMI > $35 \mathrm{~kg} / \mathrm{m}^{2}$ ) cases led to significant SUA reduction, while slight weight loss cause no change of SUA [25]. Zhu Y, et al. also claimed that weight loss of every kilogram was 
Table 2: The association between bodyweight change and UA level over 2 years

\begin{tabular}{|c|c|c|c|c|}
\hline & $\begin{array}{c}\Delta B M I \text { from } \geq 25 \\
\mathrm{~kg} / \mathrm{m}^{2} \\
\text { to }<25 \mathrm{~kg} / \mathrm{m}^{2} \\
(\mathrm{n}=1219)\end{array}$ & $\begin{array}{c}\Delta B M I \text { from BMI } \\
\quad<25 \mathrm{~kg} / \mathrm{m}^{2} \\
\text { to } \geq \mathbf{2 5} \mathrm{kg} / \mathrm{m}^{2} \\
(\mathbf{n}=\mathbf{1 7 8})\end{array}$ & $\begin{array}{c}\Delta \mathrm{BMI} \text { from } \\
\mathrm{BMI}<25 \mathrm{~kg} / \\
\mathrm{m}^{2} \text { to }<25 \mathrm{~kg} / \mathrm{m}^{2} \\
(\mathrm{n}=1118)\end{array}$ & $\begin{array}{l}\Delta B M I \text { from } \geq 25 \mathrm{~kg} / \mathrm{m}^{2} \\
\text { to } \geq 25 \mathrm{~kg} / \mathrm{m}^{2}(\mathrm{n}=\mathbf{2 1 6 3})\end{array}$ \\
\hline \multicolumn{5}{|l|}{ Age (years), Number (\%) } \\
\hline$>60$ & $51(5.06)$ & $16(9.0)$ & $677(60.6)$ & $264(12.2)$ \\
\hline $35-60$ & $963(79.9)$ & $44(24.7)$ & $262(23.4)$ & $1538(71.1)$ \\
\hline $18-35$ & $205(16.8)$ & $118(66.3)$ & $179(16.0)$ & $361(16.7)$ \\
\hline \multicolumn{5}{|l|}{ Waist circumference $(\mathrm{cm})$} \\
\hline Baseline & $93.57 \pm 13.37$ & $78.56 \pm 8.35$ & $77.56 \pm 8.35$ & $92.16 \pm 12.58$ \\
\hline Post-intervention & $82.45 \pm 9.23^{*}$ & $86.19 \pm 9.69^{*}$ & $76.32 \pm 7.79$ & $91.44 \pm 10.85$ \\
\hline \multicolumn{5}{|l|}{ SUA } \\
\hline Base line & $9.37 \pm 1.18$ & $8.26 \pm 1.23$ & $8.53 \pm 1.47$ & $9.14 \pm 1.41$ \\
\hline Post-intervention & $6.82 \pm 1.25^{*}$ & $8.14 \pm 1.58$ & $7.05 \pm 1.63^{*}$ & $8.91 \pm 1.59$ \\
\hline $\begin{array}{l}\text { Patients with normal SUA post } \\
\text { intervention, } \mathrm{n} \%\end{array}$ & $1102(90.4)$ & $35(19.7)$ & $843(75.4)$ & $775(35.8)$ \\
\hline $\begin{array}{l}\text { Patients not on urate-lowering } \\
\text { agents, } \mathrm{n} \%\end{array}$ & $311(25.5)$ & $87(48.9)$ & $346(30.9)$ & $46(2.1)$ \\
\hline
\end{tabular}

${ }^{*} \mathrm{P}<0.05$, post-intervention versus baseline.

$\triangle \mathrm{BMI}$ : the change of BMI.

associated with $11 \%$ increased odds of achieving the uratelowering goal, and these associations were independent of other risk factors [24].

In our study, middle age patients were the most likely to be overweight at the baseline, and also the most likely to get their bodyweight back to normal. SUA could be reduced with sustained increasing BMI, but in those patients, much higher proportion of urate-lowering or combined urate-lowering therapy was continued. Therefore, weight loss may be an efficient supplementary therapy to lower SUA concentrations in the obese subjects. But for the hyperuricemia patients with normal bodyweight, weight loss may not have the beneficial effect.

Waist circumference and central body fat distribution was associated with SUA [26].

Overall sedentary behavior is one of the main causes of abdominal obesity. We found that medium to heavy physical activity helps to reduce waist circumference and SUA.

Although the average BMI of Asians is lower, they demonstrate higher fat percentages compared with Caucasians of equivalent BMI [27, 28].

Nutritional education of low purine for hyperuricemia subjects or less food consumption for obesity is popular in China. However, the physical activity education is not so well conducted. Our data suggested that not just food education but also exercises should be put into the lifestyle intervention of hyperuricemia population.

When recommended with change of lifestyle behaviors, the middle age patients had higher compliance than the adolescents and old aged. It's an interesting phenomenon in the present study.

As the most affected and rapidly increased population of hyperuricemia as well as obesity, they seemed to have more concern than the other two groups of patients. Understanding of these trends helps us to make clinical decisions on different patients.

Nowadays, approximately one-third of the world's population is obese or overweight [29]. To maintain normal SUA levels, it is important for doctors to not only focus on urate-lowering medicine and nutritional education, but also to pay attention to bodyweight control and exercise. It's also important to monitor any increase trend of uric acid in obese subjects. Future studies may have to assess whether treatment strategies for the refractory hyperuricemia with obesity need to be targeted weight control as well.

One of the shortcoming of this study is the observational study design. Another shortcoming is the use of uric acid lowering treatment in a vast majority of the population, which reduced the relevance of the findings described. The analysis of the pattern of uric 
Table 3: Treatment of hyperuricemia

\begin{tabular}{lccc}
\hline & $\mathbf{B M I}<\mathbf{2 5} \mathbf{~ k g} / \mathbf{m}^{\mathbf{2}} \mathbf{( \mathbf { n } = \mathbf { 1 2 9 6 } )}$ & $\mathbf{B M I} \geq \mathbf{2 5} \mathbf{~ \mathbf { g g }} \mathbf{m}^{\mathbf{2}} \mathbf{( \mathbf { n } = \mathbf { 3 3 8 2 } )}$ & $\boldsymbol{P}$-value \\
\hline Use of allopirunol, $\mathrm{n}$ & $379(29.2)$ & $2031(60.1)$ & $<0.05$ \\
Use of febuxostat, n & $82(6.3)$ & $189(5.6)$ & $>0.05$ \\
Use of benzbromarone, $\mathrm{n}$ & $367(28.3)$ & $228(6.7)$ & $<0.05$ \\
Use of combination urate- & $35(2.7)$ & $577(17.1)$ & $<0.05$ \\
lowering therapies, n & $433(33.4)$ & $357(10.6)$ & $<0.05$ \\
Lifestyle intervention only, $\mathrm{n}$ & & & \\
\hline
\end{tabular}

Table 4: The association between physical activity and UA

\begin{tabular}{lccc}
\hline & Light activity $(\mathbf{n = 2 8 9 6 )}$ & Mediate activity (n=1300) & Heavy activity (n=482) \\
\hline Age (years), Number $(\%)$ & $747(25.8)$ & $234(18.0)$ & $27(5.6)$ \\
$>60$ & $1485(51.3)$ & $953(73.3)$ & $369(76.6)$ \\
$35-60$ & $664(22.9)$ & $113(8.7)$ & $86(17.8)$ \\
$18-35$ & $1979(68.3)$ & $851(65.5)$ & $314(65.1)$ \\
Sex $($ Male), Number $(\%)$ & & & $351(72.8)$ \\
Waist circumference, $N(\%)$ & $1287(44.4)$ & $1029(79.2)$ & $66(13.7)^{*}$ \\
Abnormal baseline & $1047(36.2)$ & $464(35.7)^{*}$ & \\
Abnormal post intervention & & & $381(79.0)$ \\
BMI $\geq 25 \mathrm{~kg} / \mathrm{m}^{2}, \mathrm{~N}(\%)$ & $1863(64.3)$ & $1138(87.5)$ & $43(8.9)^{*}$ \\
Baseline & $1626(56.1)$ & $387(29.8)^{*}$ & $416(86.3)^{*}$ \\
Post intervention & $1566(54.1)^{*}$ & $873(67.2)^{*}$ & \\
sUA $<6.0$ mg/dl, N $(\%)$ & & \\
post intervention & & & \\
\hline
\end{tabular}

${ }^{*} \mathrm{P}<0.05$, post intervention versus baseline.

acid control and bodyweight, especially in those didn't take urate-lowering agents could in part, though not fully, compensated for this limitation.

\section{MATERIALS AND METHODS}

\section{Study population}

The study included 4678 patients over 18 years old with hyperuricemia consecutively admitted to the first affiliated hospital of Sun Yat-sen University, Guangzhou, China, between January 2006 and December 2016.

In all study participants, clinical information was retrospectively investigated, including hyperuricemia and gout history, blood measures of SUA level, glucose, cholesterol, triglycerides, height, weight, systolic blood pressure (SBP), diastolic blood pressure (DBP), smoking status, alcohol consumption, and physical exercises pattern, etc.
Hyperuricemia was defined as: SUA $>7.0 \mathrm{mg} / \mathrm{dL}$ for males and SUA $>6.0 \mathrm{mg} / \mathrm{dL}$ for females $[15,16]$. Three subgroups were categorized by the concentration of SUA: (a) $\mathrm{SUA}<7 \mathrm{mg} / \mathrm{dL}$, (b) $7 \mathrm{mg} / \mathrm{dL} \leqq \mathrm{SUA}<9 \mathrm{mg} / \mathrm{dL}$, and (c) $\mathrm{SUA} \geqq 9 \mathrm{mg} / \mathrm{dL}$ [17].

Height and weight (using identical standardized anthropometric scales) were measured twice at each exam, and body mass index (BMI) was calculated as body weight $(\mathrm{kg})$ divided by height squared $\left(\mathrm{m}^{2}\right)$.

BMI was categorized into normal-weight $(\mathrm{BMI}<25$ $\mathrm{kg} / \mathrm{m}^{2}$ ) and overweight (BMI $\left.\geq 25 \mathrm{~kg} / \mathrm{m}^{2}\right)$. BMI-cutoff of obesity was BMI $\geq 30 \mathrm{~kg} / \mathrm{m}^{2}$ [18].

Physical activities were recorded and classified by frequency per week, light activity defined as less than 2 times/week with intensity of $\geq 1$ h physical exercises with prominent perspiration or breathlessness, medium activity defined as 3-5 times/week, and heavy activity defined as more than 6 times/week [19, 20].

Exclusion criteria consisted of any of the following factors: impaired renal function or impaired liver function; 
impaired heart function; patients who were taking drugs that could affect uric acid level, for example, diuretics, glyburide, Aspirin, cyclosporine A, quinolone, etc. were also excluded.

The study was conducted in accordance with the Declaration of Helsinki, and the protocol was approved by the Ethics Committee of the first affiliated hospital of Sun Yat-sen University, Guangzhou, China. (Project identification code: 165661)

\section{Statistical analysis}

Continuous variables were reported as the mean with standard deviation (SD). Chi square tests and independent sample t-tests were used to compare baseline characteristics between participants with normal-weight and overweight. $\mathrm{T}$ tests also used to compare waist circumference, SUA levels and BMI between baseline and 2-year post intervention. Linear regression was used for associated factors contributing to SUA change. Covariates were sex, age, total cholesterol, triglycerides, current smoking, physical activity, Hba1c, alcohol consumption, and waist circumference. The variables that were statistically significant by univariate analysis were added into multiple regression analysis. P-values $<0.05$ were considered statistically significant. The analyses were performed using IBM SPSS 17.0 software.

\section{Abbreviations}

body mass index (BMI), waist circumference (WC), metabolic syndrome (MetS), adenosine monophosphate protein kinase (AMPK) activity, xanthine oxidoreductase (XO), systolic blood pressure (SBP), diastolic blood pressure (DBP).

\section{Author contributions}

Fan Lian and Jun Zhou conceived and designed the research. Yu Wang, Dongying Chen, Qian Qiu, HanshiXu, Liuqin Liang and Xiuyan Yang collected the data. Jun Zhou and Yu Wang analyzed the data, Jun Zhou and Fan Lian wrote the paper.

\section{ACKNOWLEDGMENTS}

We would gratefully like to thank our co-workers, staff and participants in China.

\section{CONFLICTS OF INTEREST} interests.

\section{FUNDING}

Project supported by National Natural Science Foundation of China (No. 81102270), Guangdong Natural Science Foundation (No. 2014A030313053), and Guangdong Natural Science Foundation (No. 2016A030313217).

\section{REFERENCES}

1. Conen D, Wietlisbach V, Bovet P, Shamlaye C, Riesen W, Paccaud F, Burnier M. Prevalence of hyperuricemia and relation of serum uric acid with cardiovascular risk factors in a developing country. BMC Public Health. 2004; 4: 9.

2. Zhu Y, Pandya BJ, Choi HK. Prevalence of gout and hyperuricemia in the US general population: the National Health and Nutrition Examination Survey 2007-2008. Arthritis Rheum. 2001; 63: 3136-3141.

3. So A, Thorens B. Uric acid transport and disease. J Clin Invest. 2010; 120: 1791-1799.

4. Wang ZN, Li P, Jiang RH, Li L, Li X, Li L, Liu C, Tian $\mathrm{CL}$. The association between serum uric acid and metabolic syndrome among adolescents in northeast China. Int J Clin Exp Med. 2015; 8: 21122-21129.

5. Laine MK, Eriksson JG, Kujala UM, Wasenius NS, Kaprio J, Bäckmand HM, Peltonen M, Mertsalmi TH, Sarna S. A former career as a male elite athlete-does it protect against type 2 diabetes in later life? Diabetologia. 2014; 57: 270-274.

6. Rojas-Martínez R, Aguilar-Salinas CA, Jiménez-Corona A, Gómez-Pérez FJ, Barquera S, Lazcano-Ponce E. Prevalence of obesity and metabolic syndrome components in Mexican adults without type 2 diabetes or hypertension. Salud Pub Mex. 2012; 54: 7-12.

7. Villalobos-Molina R, Wall-Medrano A, Rodríguez-Tadeo A, Urquídez-Romero R, Hernández-Torres RP, MurguíaRomero M, iménez-Flores JR, Méndez-Cruz AR, SigristFlores SC, Medrano-Donlucas G, Díaz-Torres BA, Ramos-Jiménez A. Hypertriglyceridemic-Waist (HTGW) phenotype in university students from two regions of México. Acta Med Mediterranea. 2015; 31: 173-177.

8. Laine MK, Eriksson JG, Kujala UM, Kaprio J, Loo BM, Sundvall J, Bäckmand HM, Peltonen M, Jula A, Sarna S. Former male elite athletes have better metabolic health in late life than their controls. Scand J Med Sci Sports. 2016; 26: 284-290.

9. Haskell WL, Lee IM, Pate RR, Powell KE, Blair SN, Franklin BA, Macera CA, Heath GW, Thompson PD, Bauman A; American College of Sports Medicine; American Heart Association. Physical activity and public health: updated recommendation for adults from the American College of Sports Medicine and the American Heart Association. Circulation. 2007; 116: 1081-1093. 
10. Jung HS, Chang Y, Eun Yun K, Kim CW, Choi ES, Kwon MJ, Cho J, Zhang Y, Rampal S, Zhao D, Soo Kim H, Shin H, Guallar E, Ryu S. Impact of body mass index, metabolic health and weight change on incident diabetes in a Korean population. Obesity (Silver Spring). 2014; 22: 1880-1887.

11. Choi YJ, Shin HS, Choi HS, Park JW, Jo I, Oh ES. Uric acid induces fat accumulation via generation of endoplasmic reticulum stress and SREBP-1c activation in hepatocytes. Lab Invest. 2014; 94: 1114-1125.

12. Lanaspa MA, Sanchez-Lozada LG, Choi YJ, Cicerchi C, Kanbay M, Roncal-Jimenez CA. Uric acid induces hepatic steatosis by generation of mitochondrial oxidative stress: potential role in fructose-dependent and independent fatty liver. J Biol Chem. 2012; 287: 40732-40744.

13. Lanaspa MA, Cicerchi C, Garcia G, Li N, Roncal-Jimenez CA, Rivard CJ. Counteracting roles of AMP deaminase and AMP kinase in the development of fatty liver. PLoS One. 2012; 7: e48801.

14. Cheung KJ, Tzameli I, Pissios P, Rovira L, Gavrilova O, Ohtsubo T. Xanthine oxidoreductase is a regulator of adipogenesis and PPARr activity. Cell Metab. 2007; 5: 115-128.

15. Lin CS, Hung YJ, Chen GY, Tzeng TF, Lee DY, Chen CY, Huang WP, Huang CH. A multicenter study of the association of serum uric acid, serum creatinine, and diuretic use in hypertensive patients. Int J Cardiol. 2011; 148: 325-330.

16. Sonoda H, Takase H, Dohi Y, Kimura G. Uric acid levels predict future development of chronic kidney disease. Am J Nephrol. 2011; 33: 352-357.

17. Obermayr RP, Temml C, Gutjahr G, Knechtelsdorfer M, Oberbauer R, Klauser-Braun R. Elevated uric acid increases the risk for kidney disease. J Am Soc Nephrol. 2008; 19: 2407-2413.

18. Wu Y. Overweight and obesity in China. BMJ. 2006;333: 362-363.

19. Norvik JV, Storhaug HM, Ytrehus K, Jenssen TG, Zykova SN, Eriksen BO, Solbu MD. Overweight modifies the longitudinal association between uric acid and some components of the metabolic syndrome: the troms $\varnothing$ study. BMC Cardiovasc Disord. 2016; 16: 85.

20. Ahmed AM, Elabid BE, Elhassan KE, Waggiallah HA. Metabolic syndrome among undergraduate students attending medical clinics for obligatory medical screening. Trop J Pharm Res. 2015; 14: 317-321.

21. Remedios $C$, Shah M, Bhasker AG, Lakdawala $M$. Hyperuricemia: a reality in the Indian obese. Obes Surg. 2012; 22: 945-948.

22. Liu L, Lou S, Xu K, Meng Z, Zhang Q, Song K. Relationship between lifestyle choices and hyperuricemia in Chinese men and women. Clin Rheumatol. 2013; 32: 233-239.

23. Palmer TM, Nordestgaard BG, Benn M, Tybjærg-Hansen A, Davey Smith G, Lawlor D, Timpson NJ. Association of plasma uric acid with ischaemic heart disease and blood pressure: mendelian randomisation analysis of two large cohorts. BMJ. 2013; 347: f4262.

24. Zhu Y, Zhang Y, Choi HK. The serum urate-lowering impact of weight loss among men with a high cardiovascular risk profile: the Multiple Risk Factor Intervention Trial. Rheumatology (Oxford). 2010; 49: 2391-2399.

25. Dalbeth N, Chen P, White M, Gamble GD, Barratt-Boyes C, Gow PJ, Orr-Walker B. Impact of bariatric surgery on serum urate targets in people with morbid obesity and diabetes: a prospective longitudinal study. Ann Rheum Dis. 2014; 73: 797-802.

26. Ford ES, Li C, Cook S, Choi HK. Serum concentrations of uric acid and the metabolic syndrome among us children and adolescents. Circulation. 2007; 115: 2526-2532.

27. Park YW, Allison DB, Heymsfield SB, Gallagher D. Larger amounts of visceral adipose tissue in Asian Americans. Obes Res. 2001; 9: 381-387.

28. Khoo CM, Sairazi S, Taslim S, Mullany EC, Biryukov S, Abbafati C, Abera SF, Abraham JP, Abu-Rmeileh NM, Achoki T. Ethnicity modifies the relationships of insulin resistance, inflammation, and adiponectin with obesity in a multiethnic Asian population. Diabetes Care. 2011; 34: $1120-1126$.

29. Ng M, Fleming T, Robinson M, Thomson B, Graetz N, Margono C, Mullany EC, Biryukov S, Abbafati C, Abera SF, Abraham JP, Abu-Rmeileh NM, Achoki T. Global, regional, and national prevalence of overweight and obesity in children and adults during 1980-2013: a systematic analysis for the Global Burden of Disease Study 2013. Lancet. 2014; 384: 766-781. 